communities, and bringing forward a health system to be proactive in determining the rural health agenda. Opportunities exist and to a limited extent, are being exploited. Community 'health councils', rural health training, and an evolving level of rural health research are all signs for optimism.

The further groundwork for change must be laid. Ongoing recognition of stratified indicators of rural health is necessary. Most importantly, however, is the need to listen to and work with communities. Disadvantaged groups should be encouraged to actively participate in developing policy, and implementing measures intended to improve their situation. ${ }^{4}$ These programs and interventions must be implemented in a way that supports equity and group problem solving. Regionally based, and central policy-makers need to encourage and facilitate rural communities that advocate for change. While early steps have been taken, and have provided some measure of optimism, in order to achieve a more equitable and focused policy framework to develop better rural health, a deepening of understanding and a greater willingness to be 'with' rural communities in their plight remains a priority.

\section{REFERENCES}

1. Lawson H. Faces in the Street (1888). Wright DM (editor). In the days when the world was wide: the poetical works of Henry Lawson. Melbourne: Lloyd O’Neill: 1970.

2. Reeves PN, Coile RC. Introduction to Health Planning (4th edition). Arlington, Virginia: Information Resources Press, 1989.

3. Kerr DH. The logic of Policy and Successful Policy. Policy Sciences September 1976; 7 (3): 351-363.

4. Werner D, Saunders D. Questioning the Solution: The politics of Primary Health Care and Child Survival. Palo Alto, California: HealthWrights, 1997.

5. Douglas M. Restriction of the hours of sale of alcohol in a small community: A beneficial impact. Aust N Z J Public Health 1998; 22: 714-9. 保

\title{
THE EXPERIENCE OF THE WELL PERSON'S HEALTH CHECK INTHE FAR WEST AREA HEALTH SERVICE
}

\section{Lisa Jackson * \\ NSW Public Health Officer Training Program \\ NSW Department of Health}

\section{Darren Mayne and Hugh Burke}

Far West Area Health Service

The Far West Area Health Service (FWAHS) sought to develop a new, or implement a modified, community screening methodology to assist in assessing the health needs of remote Aboriginal communities living within its area. Following a review of the literature, it was decided to examine the North Queensland Well Person's Health Check, which is run in collaboration between the Tropical Public Health Unit (TPHU) in Cairns and the Apunipima Cape York Health Council, a community-controlled indigenous health organisation in Far Northern Queensland. This article describes the process by which the FWAHS adopted its own Far West Well Person's Health Check (Far West WPHC).

\section{THE WELL PERSON'S HEALTH CHECK IN NORTH QUEENSLAND}

The original Well Person's Health Check was developed in Far North Queensland following the publication of the National Aboriginal Health Strategy in 1988. Findings of the Strategy confirmed that many undiagnosed and untreated diseases such as sexually transmitted infections, diabetes, renal, cardiovascular and respiratory disease contribute substantially to excess mortality and morbidity in indigenous populations. Treatment of these diseases in the early stages can result in a cure or a reduction in morbidity. Unfortunately, because many of these diseases are initially asymptomatic, diagnosis usually occurs at a later stage.

To promote community-based primary health care, a unique partnership was formed during 1997 with the Apunipima Cape York Health Council and the TPHU. One of the outcomes of this partnership was the development of the Far North Queensland Well Person's Health Check. This intervention, originally targeted at remote communities, was an endeavour to:

- establish the extent of certain diseases in remote communities;

- provide early treatment and referral;

- use the data collected to inform service delivery and address local health issues.

The program is planned and implemented in conjunction with local community members and service providers. The Well Person's Health Check is conducted in conjunction with a community event in order to attract interest and optimise participation. Well Person's screening is offered together with health promotion activities, advice, treatment, and healthy food. There are protocols for consent and confidentiality, and referral and follow-up treatment are provided.

Currently Epidemiologist at the South Eastern Sydney Public Health Unit. 


\section{THE WELL PERSON'S HEALTH CHECK INTHE FAR WEST OF NSW}

A working party consisting of representatives from Maari Ma Health Aboriginal Corporation, the University of Sydney's Department of Rural Health (Broken Hill), and the Division of Population Health (Far West Area Health Service) was convened to guide the adaptation of the North Queensland Well Person's Health Check to better suit the needs and resources of an Aboriginal community in the Far West of NSW. The working party decided to pilot a program in a community that fulfilled the following criteria:

- a remote community in the Far West Area Health Service;

- a majority population (75 per cent) of persons of Aboriginal descent;

- the presence of a health service, hospital or mutipurpose health facility;

- the presence of a general practitioner in residence or access to regular Royal Flying Doctor Service clinics.

Community consultation was held in two communities: Dareton, near Mildura; and Goodooga, near Lightning Ridge. Members of each community were given letters outlining the project.

All aspects of the Far West WPHC were explained to health staff, health advisory council members, and community groups including the elders, the justice committee and others. Discussion included the roles of collaborating organisations, the process of community consultation, the perceived time-line, outcomes and logistics. The Goodooga community decided to host the Far West WPHC pilot program. The following objectives arose from community expectations:

- detection and early intervention in diabetes, renal disease, hypertension, and sexually transmitted infections;

- performing a brief dental examination;

- providing health information to those at risk of disease;

- achieving a reduction in the prevalence of preventable disease;

- focussing community attention on health and related issues;

- assist future planning by providing baseline data for health service delivery throughout the region;

- building capacity of health workers, community members and local health services;

- detection and treatment of some asymptomatic diseases;

- referrals to clinics and other providers for ongoing care and treatment for those detected with disease;
- provision of brief interventions for smoking, nutrition, alcohol and sexual health matters.

\section{STAGE ONE: NOVEMBER 1999TO APRIL 2000}

The Health Advisory Council, the Goodooga Working Party, staff of the Goodooga and Lightning Ridge Health Services, and community members, worked together to ensure the community consultation was thorough. This took over four months, from the first contact to the first day of the Far West WPHC.

A community survey involving a simple questionnaire was done some weeks before the Far West WPHC. Each household was given a community information booklet and a large poster to keep. Individuals in the target age group (15 to 45) were identified and compared to the most recent census. This became the screening denominator.

An artwork competition valued at $\$ 250$ was held for the design of a Far West WPHC T-shirt, which also served to galvanise community interest. The winning entry became the official artwork of the Far West WPHC in Goodooga.

In preparation, all people working on the Far West WPHC attended a specially designed two-and-a-half day course at the Goodooga Health Service developed by the Department of Rural Health at the University of Sydney. The emphasis was on developing the practical skills of staff and community members of the Goodooga area. A certificate of participation was awarded to each person who attended the training program.

A community event was held immediately before the Far West WPHC, which included a talent quest, ball games, races, and a band performance. Other groups, including the Aboriginal and Torres Strait Islander Commission, the police, fire brigade, and the local school, donated services and prizes to the talent quest. Elders prepared bush foods including Етu in the Hole (traditionally prepared bush tucker) and Johnny Cakes (a damper style bread). Members of the Far West WPHC team handed out brochures, leaflets and other health-related materials, and answered any questions people had about the Far West WPHC.

\section{STAGE TWO: MAY-JUNE 2000}

The Far West WPHC was set up in the demountable building at the Goodooga Health Service. Each person went through nine stations, with each station focusing on different health related questions and examinations:

- Consent: Written consent was obtained from each person. Consent could be withdrawn at any time, for all or part of the Far West WPHC.

- Registration Information: Each person's contact details were checked so that staff could follow up on the results.

- Blood Pressure: Blood pressure was taken three times to calculate the average systolic and diastolic blood pressure. 
- Anthropometry: Body Mass Index (BMI) and Waist Hip Ratios (WHR) were calculated from height, weight, waist and hip measurements.

- Oral Health: Visual assessment of oral hygiene, including, examination of teeth, gums, mucosa and tongue. Opportunistic feedback was given regarding oral care.

- Blood Collection: Fasting blood glucose levels, liver function, total cholesterol and triglicerides, red blood cells, serum folate levels, and an examination for syphilis, were conducted on the $25 \mathrm{ml}$ of blood taken from each individual.

- Urine Sample: Mid-stream urine was collected to conduct a polymerase chain reaction (PCR) test for gonorrhea and chlamydia, and albumin creatinin ratio (ACR); and urinary iodide was also measured.

- Lifestyle Interview: Questions were asked about cigarette smoking, alcohol consumption, fruit and vegetable intake, and levels of exercise.

- Exit Interview: Questions about medical background and medication regimes were asked; and assessments were made as to whether the person would be eligible for vaccination or required referrals to other healthrelated services. Some feedback on the anthropometry, blood pressure, alcohol and smoking were given.

The Far West WPHC was open for 10 days from 5.00 or 6.00 a.m. to midday each day. All people over the age of 15 years were invited to attend. Between 25-35 people were screened each day.

Following completion of the check, each person received a healthy breakfast of stew, fresh fruit, cereals, breads and juices. They also received a T-shirt featuring the artwork of the Goodooga Far West WPHC.

\section{STAGETHREE: JUNE 2000}

\section{Clinical follow-up}

The majority of people who attended Stage Two of the Far West WPHC attended a clinical follow-up. Two confidential consultations with a clinician were provided, and immediate treatment or further investigation was offered to those with equivocal fasting blood glucose levels, or to those with any sexually transmissible infection. Vaccination against influenza and pneumonia where offered where indicated.

\section{Nutritional session}

A nutritional session, conducted by a nutritionist from Broken Hill, was offered to each person who attended the Far West WPHC. An individualised booklet outlining both their self-reported and observed information (other than information related to sexually transmissible infections) was provided for each participant. Each booklet contained:

- self-reported fruit and vegetable intake, smoking and alcohol use, and amount of exercise;
- observed weight, body shape, blood pressure, and oral health status;

- laboratory results of red cell folate, blood fats, blood glucose levels, and liver and kidney function;

- health information, including nutrition and exercise tips.

A small dilly bag was given to each person, which contained other health-related information; fruit, oral care products and follow-up cards. People who could not attend this session were offered alternative sessions by the health staff who conducted the Far West WPHC program.

\section{Diabetic morning tea}

A special diabetic morning tea was held for those interested, including newly-diagnosed diabetics, and people with equivocal blood glucose levels. An informal discussion about food, eating, exercise, and alcohol occurred, while participants made snacks and lunches from locally-acquired foods.

\section{COMMUNITY REPORT AND SUBSEQUENT INTERVENTIONS}

Aggregated data about the Goodooga community was presented to the community both as a written and oral report during August 2000. This information has been disseminated through the Goodooga Health Advisory Council.

A number of short, community-based interventions have started locally in response to the findings of the Far West WPHC.

\section{CONCLUSION}

Information gathered during the Far West WPHC is now the base-line data for the Goodooga community, which describes the current state of the health and wellbeing of that particular community. The community uses this data to lobby for additional services and for funding for specific projects. Service providers and the community can use this information to better plan and implement appropriate health programs, and to allocate resources more effectively.

This type of program is an important step in health service planning and delivery. During the consultation phase of the project, one man summed up the intention of the Far West WPHC:

'Our people die earlier than other Australians. People die from things that can be prevented. It is not fair. We need proper support to stop this from happening. It's not about research, it's about the stuff we can do to get what we need: not what others think we need.'

Programs like the Far West WPHC are an important step in supporting our health services in knowing what services remote communities need to stay well. 


\section{ACKNOWLEDGEMENTS}

We would like to acknowledge the invaluable assistance and support of the elders and residents of Goodooga; the Namitjira Avenue Working Party (Dareton); the Apunipima Cape York Health Council, the Tropical Public Health Unit in Cairns; the members of the Far North Queensland Well Person's Health Check Team, Pormpuraaw; the members and representative organisations of the steering committee in Broken Hill, and the dedicated team of the Far West Well Person's Health Check in Goodooga.

We would also like to acknowledge the NSW Public Health Officer's Training Program for giving Lisa Jackson the opportunity to work in the Far West Area Health Service.

\section{THE HEALTH OF THE PEOPLE IN AGRICULTURE AND ITS}

INTERDEPENDENCE WITH THE HEALTH OF RURAL COMMUNITIES

\section{Lyn Fragar}

Australian Centre for Agricultural Health and Safety University of Sydney, Moree

This article describes the factors that are driving change in Australian agriculture, how they affect the health of the agricultural population and of rural communities as a whole.

\section{BACKGROUND}

Australian agriculture comprises a large number of discrete rural industries. While there are some similarities between these industries (such as outdoor work, the use of mobile plant and equipment, and often the structure of a family business), there are many differences between their production processes and enterprise arrangements. For example, the production processes and labour arrangements of a dairy enterprise contrast markedly with those of a cotton or vegetable enterprise.

Further, agriculture industries are in constant change and, while these changes affect the social wellbeing and health of people in those industries, constant change also affects the social and economic position of the wider rural community. A number of factors have been identified as driving change and the restructuring

\section{FIGURE 1}

PRODUCTION INDICES IN AUSTRALIAN AGRICULTURE BY FISCAL YEARS, 1970-1998

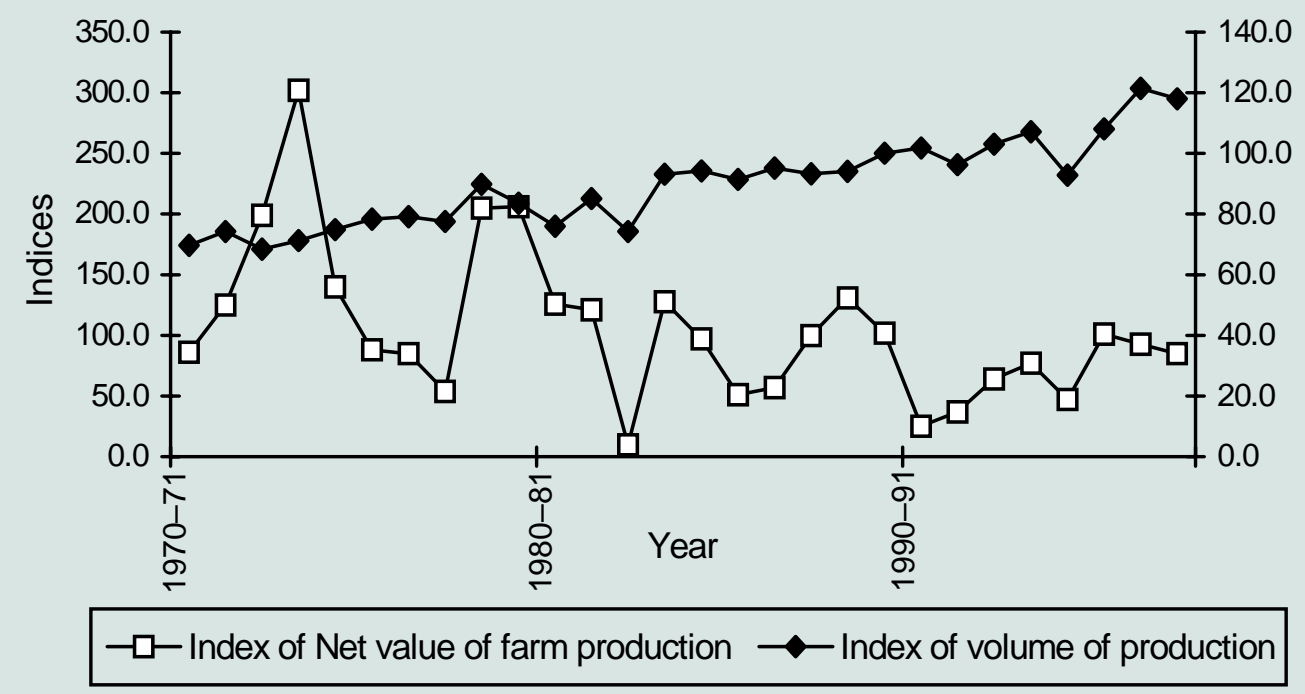

Data Source: Australian Bureau of Agricultural and Resource Economics, $1998 .^{4}$ 